\title{
KHAI THÁC DŨ̃ LIỆU LƯợNG MƯA GẦN THỜI GIAN THỰC TỬ DŨ̉ LIỆU VIỄN THÁM PHỤC VỤ CÔNG TÁC GIÁM SÁT, DỤ๋ BÁO VÀ CẢNH BÁO LŨ LỤT TRONG HỆ THỐNG PHÂN TÍCH LŨ LỤT TÍCH HỢP - IFAS
}

TS. NGUYẼ̃N XUÂN LÂM, TS. LÊ QUÓC HƯNG, CN. LÊ MINH SƠN

Cục Viễn thám Quốc gia

\section{Tóm tắt:}

Dữ liệu mưa là dữ liệu quan trọng trong quy hoạch quản lý tài nguyên nước cũng như giảm thiểu tác động do thiên tai gây ra. Do đó, công tác quan trắc mưa có vai trò hết sức quan trọng. Quan trắc mưa hiện nay gồm các phương pháp chính: phương pháp đo mưa tại chỗ; phương pháp đo mưa bằng hệ thống radar thời tiết; phương pháp đo mura bằng công nghệ viễn thám. Hai phương pháp đầu tuy có độ chính xác cao nhưng gặp phải khó khăn rất lớn khi đo đạc tại các khu vực hiểm trở, vùng đồi núi và trên biển. Trong khi đó, phương pháp sưr dụng công nghệ viễn thám đã, đang được nghiên cứu và phát triển mạnh mẽ, trở thành công cụ hữu ích trong quản lý tài nguyên nước và giảm thiểu thiệt hại do thiên tai, nhất là trong tình hình tác động của biến đổi khí hậu ngày càng nghiêm trọng. Đặc biệt, phương pháp đo mura bằng công nghệ viễn thám có thể kết hợp với các mô hình giám sát, dự báo và cảnh báo thiên tai như lũ lụt và hạn hán. Bài báo sẽ mô tả mô hình chiết tách lượng mưa gần thời gian thực bằng công nghệ viễn thám khi kết hợp dữ liệu viễn thám hồng ngoại và dữ liệu viễn thám radar. Đồng thời, việc khai thác sử dụng dữ liệu chiết xuất này cũng được giới thiệu thông qua Hệ thống phân tích lũ tích hợp - IFAS (Integrated Flood Analysis System).

\section{Giới thiệu}

$\square-$ ể quan trắc lượng mưa, có ba phương pháp chính : đo mưa tại chỗ bằng dụng cụ đo, đo mưa bằng hệ thống radar thời tiết và sử dụng công nghệ viễn thám để quan trắc mưa. Mỗi phương pháp đều có ưu, khuyết điểm riêng nên trong thực tế cả 3 phương pháp đều được sử dụng rộng rãi.

Phương pháp đo mưa tại chỗ có nhược điểm là kết quả đo mưa của điểm rời rạc nên muốn tính lượng mưa cho toàn khu vực ta phải tính giá trị trung bình hoặc sử dụng phương pháp nội suy để tính phân bố mưa theo không gian. Thêm nữa, các trạm đo mưa thường được lắp đặt tại hoặc gần những khu vực đô thị do thuận tiện trong công tác lấy số liệu cũng như bảo trì. Tuy

nhiên, hầu hết thiên tai liên quan đến yếu tố mưa đều xảy ra ở vùng sâu, vùng xa hoặc các trận mưa lớn hình thành trên biển và di chuyển vào đất liền, nên việc sử dụng dư liệu đo mưa tại chỗ có nhiều trở ngại trong công tác cảnh báo thiên tai, đặt biệt là lũ nói chung và lũ quét nói riêng (lũ quét hình thành do sự cố vỡ đập hoặc mưa cường độ lớn, trong thời gian ngắn - thường trong vòng vài giờ, trên địa hình dốc). Đo mưa tại chỗ là phương pháp duy nhất đo mưa trực tiếp nên rất đáng tin cậy nên dữ liệu đo mưa tại chỗ được sử dụng để hiệu chỉnh trong tính toán mưa của các phương pháp đo mưa gián tiếp.

Đo mưa bằng hệ thống radar thời tiết có ưu điểm là cho kết quả đo trực tuyến, độ chính xác cao, với độ phân giải không gian và thời gian cao ( 1 km, 5-10 phút), khu vực 
bao phủ rộng lớn (100 - 200km) nên thuận lợi trong vấn đề dự báo và theo dõi diễn biến thiên tai trong thời gian dài. Nhiều nước và vùng lãnh thổ (Mỹ, Anh, Hà Lan, Nhật, Đài Loan, Hồng Kông ...) đã xây dựng thành công các hệ thống cảnh báo sớm thiên tai dựa vào dữ liệu mưa chủ yếu từ hệ thống radar. Tuy nhiên, radar thường hoạt động không tốt ở khu vực địa hình đồi núi, không phủ tới vùng sâu, vùng xa, trên mặt biển, khó quản lý và vận hành tốn kém.

Nhìn chung, hai phương pháp đo mưa trên đều gặp rất nhiều hạn chế trong việc quan trắc mưa tại vùng sâu, vùng $x a$, vùng đồi núi và trên biển. Để giải quyết vấn đề này, phương pháp thứ ba, sử dụng công nghệ viễn thám đang là biện pháp khả thi và được ứng dụng ngày càng rộng rãi. Ngay từ những năm 1960, công nghệ viễn thám đã bắt đầu được nghiên cứu ứng dụng trong theo dõi thời tiết, đặc biệt là mưa với viễn thám hồng ngoại và viễn thám radar. Với sự phát triển mạnh mẽ của công nghệ vũ trụ và khoa học tính toán, nhiều thuật toán, phương pháp đã được xây dựng để tính toán lượng mưa từ dữ liệu vệ tinh với độ chính xác ngày càng được nâng cao.

\section{Xác định lượng mưa gần thời gian thực bằng công nghệ viễn thám}

2.1. Tổng quan xác định lượng mưa bằng công nghệ viến thám. (Xem hình 1)

Xác định lượng mưa bằng viễn thám hồng ngoại từ các vệ tinh GEO cho thông tin về nhiệt độ bề mặt (phía trên) của các đám mây để tính toán lượng mưa với nhận định rằng cường độ mưa tỉ lệ nghịch với nhiệt độ bề mặt đám mây - hay đám mây có nhiệt độ bề mặt càng thấp thì gây mưa càng lớn. Nhiều nghiên cứu đã chỉ ra rằng, các thuật toán tính mưa từ ảnh vệ tinh GEO phổ hồng ngoại hiệu quả trong vấn đề tính toán mưa đối lưu vùng nhiệt đới nhưng xuất hiện sai số lớn bởi ảnh hưởng mây ở tầng cao (Arkin và Meisner, 1987; Adler và Negri, 1988). Kỹ thuật phân loại mây dựa vào các thông số về đặc điểm mây được sử dụng để cải thiện kết quả tính mưa. Việc kết hợp thông tin ảnh chụp từ nhiều phổ khác nhau cũng mang lại kết quả tốt hơn (Ba và Gruber, 2001; Bellerby và cs., 2000; Bellerby, 2004; Capacci và Conway, 2005; Hong và cs., 2004; Hsu và cs., 1999; Turk và Miller, 2005).

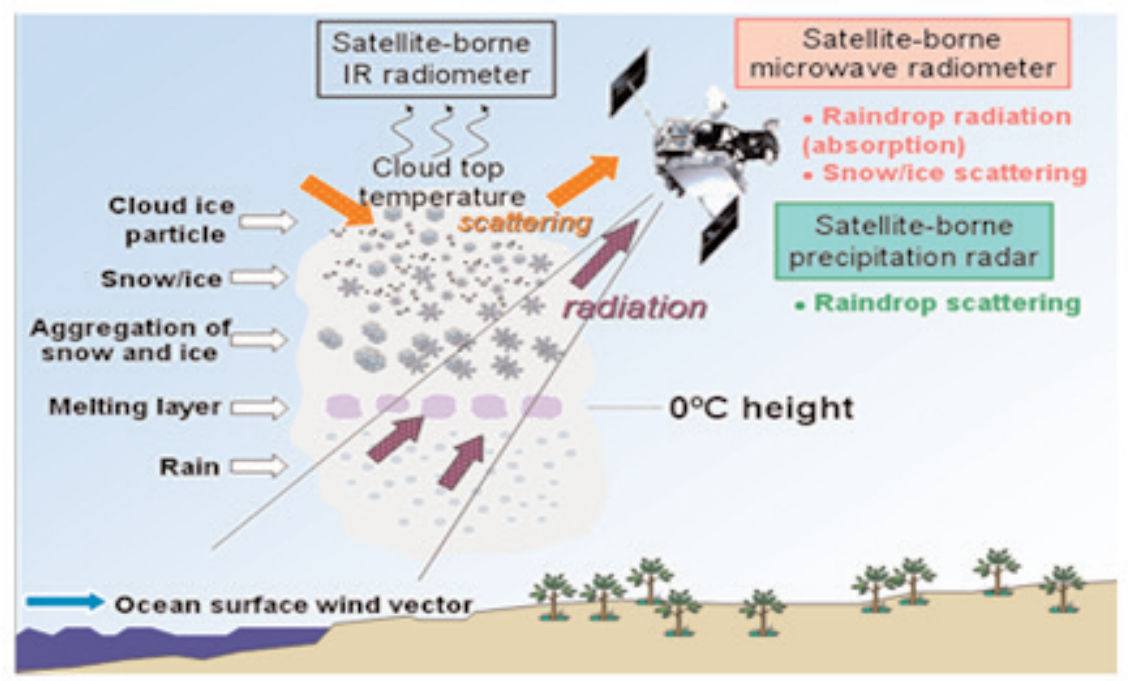

Hình 1: Nguyên lý theo dõi mưa của vệ tinh 
Bên cạnh viễn thám hồng ngoại, viễn thám radar từ dữ liệu vệ tinh LEO với các cảm biến thu nhận năng lượng bức xạ nhiệt từ các hạt mưa ở bước sóng microwave (Passive Microwave - PMW). Cảm biến của vệ tinh LEO thu nhận tín hiệu PMW cung cấp thông tin chi tiết hơn về cấu trúc của các đám mây. Ảnh vệ tinh GEO với diện tích bao phủ toàn bộ bề mặt địa cầu nhưng kết quả tính mưa với độ chính xác không cao, còn ảnh vệ tinh LEO cho thông tin về mưa chính xác hơn nhưng diện tích bao phủ nhỏ tại một thời điểm. Do đó, việc kết hợp ảnh vệ tinh LEO để hiệu chỉnh các khu vực tương ứng của ảnh vệ tinh GEO đã đem lại kết quả tính mưa được cải thiện đáng kể (Ba và Gruber, 2001; Bellerby và cs., 2000; Bellerby, 2004; Hsu và cs., 1997; Huffman và cs., 2007; Kidd và cs., 2003; Marzano và cs., 2004; Nicholsonvà cs., 2003a, 2003b; Sorooshian và cs., 2000; Todd và cs., 2001; Turk và Miller, 2005; Vicente và cs., 1998).

Các nghiên cứu gần đây đã chỉ ra hiệu quả của việc sử dụng ảnh vệ tinh LEO kết hợp với ảnh vệ tinh GEO. Trung tâm Dự báo khí hậu (Climate Prediction Center) sử dụng phương pháp nội suy tuyến tính để hiệu chỉnh ảnh GEO-IR theo ảnh LEO-PMW ở những vùng ảnh tương ứng để cho ra dữ liệu mưa CMORPH (Joyce và cs., 2004). Phương pháp lọc Kalman (Kalman filter) đang được phát triển để nâng cao chất lượng dữ liệu CMORPH (Joyce và cs., 2008; Okamoto và cs., 2005). Một số nghiên cứu cho rằng việc sử dụng mô hình đơn giản về sự phát triển của một trận mưa giữa các dải quét của vệ tinh LEO sẽ cho kết quả tốt hơn là sử dụng phương pháp nội suy hay cập nhật. Phương pháp này sử dụng quan hệ của những thay đổi trong đặc điểm bề mặt các đám mây và các quá trình hình thành mưa để tính lượng mưa hơn là dựa vào quan hệ tĩnh giữa ảnh GEO-IR và mưa (Machado và cs., 1998; Horsfield, 2006;
Bellerby và cs., 2009; Hsu và cs., 2009; Behrangi và cs., 2010).

Chương trình đo mưa nhiệt đới (Tropical Rainfall Measurement Mission - TRMM) do NASA hợp tác với JAXA (Nhật Bản) thực hiện từ năm 1997 đã sử dụng vệ tinh LEO để đo mưa cho khu vực nhiệt đới $\left(38^{\circ} \mathrm{Nam}\right.$ - $38^{\circ}$ Bắc) với độ chính xác được nâng cao (Kummerow và cs., 1998; Kummerow và cs., 2000; Simpson và cs., 1988). Hệ thống vệ tinh LEO trong chương trình Đo mưa toàn cầu (Global Precipitation Measurement - GPM) theo kế hoạch sẽ được phóng vào năm 2014. Nhờ có nhiều vệ tinh nên hệ thống GPM sẽ cho ảnh với độ phân giải thời gian ngắn (3 giờ), bao phủ khoảng $90 \%$ diện tích bề mặt địa cầu. Hệ thống GPM được kỳ vọng sẽ mang lại nhiều thành tựu to lớn trong việc quan trắc mưa trên toàn cầu.

Dưới đây, xin giới thiệu phương pháp xác định lượng mưa gần thời gian thực bằng công nghệ viễn thám kết hợp viễn thám hồng ngoại và viễn thám radar nhằm phục vụ công tác phòng chống giảm nhẹ thiên tai do lũ lụt. Mô hình kết hợp có thể ở dạng 2 loại dữ liệu viễn thám hoặc nhiều loại dữ liệu viễn thám khác nhau.

2.2. Mô hình chiết xuất thông tin lượng mưa gần thời gian thực từ 2 loại dữ liệu vệ thám - MTSAT và TRMM $2 A 12$

Ảnh MTSAT với độ phân giải thời gian là 30 phút cho khu vực Bắc bán cầu và 1 giờ cho toàn bộ bán cầu, cho phép JMA có thể giám sát chặt chễ hơn sự di chuyển của bão và các đám mây. (Xem bảng 1)

TRMM là vệ tinh quan sát trái đất đầu tiên được thiết kế bởi NASA và JAXA với nhiệm vụ theo dõi và nghiên cứu lượng mưa nhiệt đới, phục vụ mục đích theo dõi biến đổi khí hậu và môi trường trên toàn cầu. Vệ tinh TRMM gồm năm đầu thu: Precipitation radar (PR), TRMM Microwave Imager (TMI), Visible and Infrared Scanner 
(VISR), Clouds and the Earth's Radiant Energy System (CERES) and Lightning Imaging Sensor (LIS). Tuy nhiên trong nghiên cứu này, tác giả tập trung vào dư liệu sản phẩm TRMM 2A12 của đầu thu TMI. Dữ liệu TRMM 2A12 với thông tin lượng mưa theo thời gian thực ước tính từ đầu thu TMI gồm có 14 kênh chứa một số các thông số vật lý như: mây chứa nước, nước mưa, đám mây băng, mưa đá, cường độ mưa trên bề mặt $(\mathrm{mm} / \mathrm{h})$, mưa đối lưu... Dữ liệu thu được sẽ sử dụng với các thuật toán khác nhau cho mục đích tính mưa ở các khu vực khác nhau như đất liền hay đại dương.(Xem bảng 2)

Như đã giới thiệu ở trên, phương pháp viễn thám hồng ngoại nhiệt và radar đều có những ưu nhược điểm riêng, việc kết hợp hai phương pháp sẽ nâng cao chất lượng của kết quả tính toán lượng mưa. Mô hình kết hợp 2 loại dữ liệu hồng ngoại nhiệt MTSAT kết hợp với dữ liệu radar - TRMM 2A12 được mô tả trong hình 2. (Xem hình 2)

Bảng 1: Thông số cơ bản của vệ tinh MTSAT

\begin{tabular}{|c|c|c|c|c|c|}
\hline $\begin{array}{l}\text { Kênh và bước } \\
\text { sóng }\left(\begin{array}{ll}\mu & 1\end{array}\right)\end{array}$ & $\begin{array}{l}\text { VIS } \\
0.55-0.90\end{array}$ & $\begin{array}{l}\text { IR1 } \\
10.3-11.3\end{array}$ & $\begin{array}{l}\text { IR2 } \\
11.5-12.5\end{array}$ & $\begin{array}{l}\text { IR3 } \\
6.5-7.0\end{array}$ & $\begin{array}{l}\text { IR4 } \\
3.5-4.0\end{array}$ \\
\hline & \multicolumn{5}{|c|}{1 km (VIS) và 4 km (IR) } \\
\hline & \multicolumn{5}{|c|}{10 bits đối với kênh VIS và IR (1,024 gradations) } \\
\hline & \multicolumn{5}{|c|}{$\begin{array}{l}\text { S-band (Tiếp nhận: 2026-2035 MHz, truyền tải: 1677-1695 MHz) UHF (Tiếp } \\
\text { nhận: } 402 \mathrm{MHz} \text {, truyền tải: } 468 \mathrm{MHz} \text { ) }\end{array}$} \\
\hline
\end{tabular}

Bảng 2: Thông số kỹ thuật của đầu thu TMI (TRMM)

\begin{tabular}{|c|c|c|c|c|}
\hline Kênh & Tần số hoạt động $(\mathrm{GHz})$ & Phân cực & Độ rộng giải chụp $(\mathrm{km})$ & Mục tiêu \\
\hline 1 & 10.65 & $\mathrm{~V}$ & 36.8 & Mưa rất mạnh \\
\hline 2 & 10.65 & $\mathrm{H}$ & 36.8 & Mưa rất mạnh \\
\hline 3 & 19.35 & $\mathrm{~V}$ & 18.4 & Mưa mạnh \\
\hline 4 & 19.35 & $\mathrm{H}$ & 18.4 & Mưa mạnh \\
\hline 5 & 21.3 & $\mathrm{~V}$ & 18.4 & Mưa bình thường \\
\hline 6 & 37 & $\mathrm{~V}$ & 9.2 & Mưa nhẹ \\
\hline 7 & 37 & $\mathrm{H}$ & 9.2 & Mưa nhẹ \\
\hline 8 & 85.5 & $\mathrm{~V}$ & 4.6 & Mưa mạnh, Mưa nhẹ \\
\hline 9 & 85.5 & $\mathrm{H}$ & 4.6 & Mưa mạnh, Mưa nhẹ \\
\hline
\end{tabular}


Hình 2: Mô hình chiết xuất thông tin lượng mưa gần thời gian thực từ dữ liệu vệ tinh MTSAT kết hợp với dữ liệu TRMM $2 A 12$

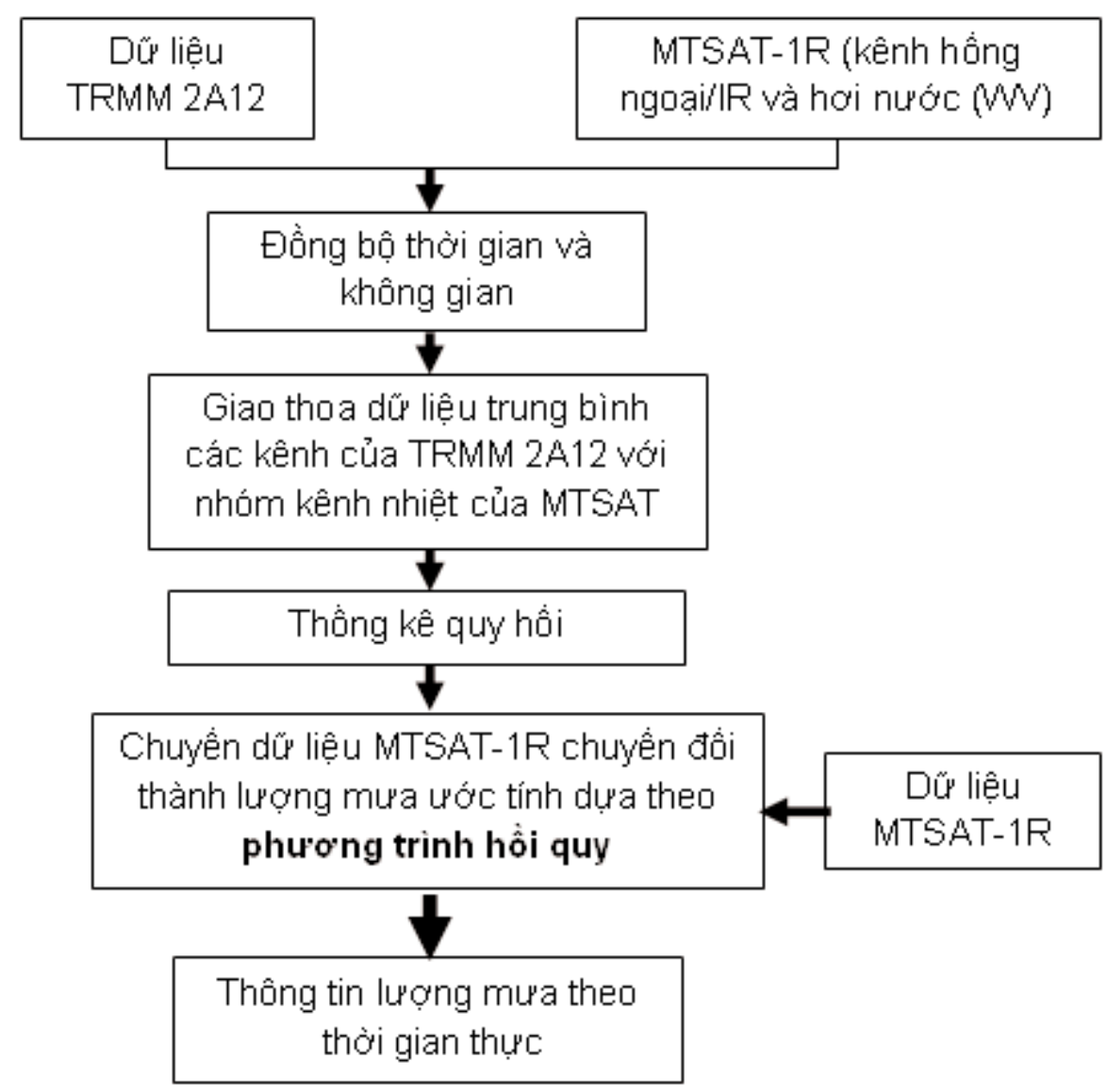

Thông tin lượng mưa gần thời gian thực được chiết xuất từ sự kết hợp hai nguồn dữ liệu MTSAT và TRM 2A12 dựa trên phương pháp kết hợp của Maathuis (2006). Thực tế phương pháp này ứng dụng để kết hợp dữ liệu MSG với dữ liệu TRMM 2A12. Đặc điểm chính của phương pháp này là sự phát triển của mối quan hệ thống kê giữa MSG và TRMM bằng cách kết hợp nhóm dữ liệu hồng ngoại của MSG với dữ liệu lấy trung bình của TRMM. Dựa trên phương pháp này, tác giả đã thay thế dữ liệu MSG bằng dữ liệu MTSAT với các kênh tương ứng.

Thực tế việc tích hợp hai nguồn dữ liệu MTSAT và TRMM 2A12 để chiết xuất thông tin lượng mưa có thể chia làm 3 bước cơ bản:
- Đồng bộ dữ liệu theo không gian và thời gian

- Mối quan hệ thống kê (statistical relationship)

- Chuyển đổi dữ liệu.

2.3. Mô hình chiết xuất thông tin lượng mưa gần thời gian thực từ 2 loại dữ liệu vệ thám - Hệ thống GSMaP

Hệ thống GSMaP được phát triển dựa trên các hoạt động của dự án GSMaP JSTCREST (Bản đồ vệ tinh lượng mưa toàn cầu). Dự án được tài trợ bởi Cơ quan Khoa học và Công nghệ Nhật Bản (JST), được nghiên cứu từ năm 2002 và được đưa vào hoạt động trên trang Web 
http://sharaku.eorc.jaxa.jp/GSMaP/ từ năm 2007.

GSMaP cung cấp theo giờ bản đồ lượng mưa toàn cầu trong thời gian gần thực (khoảng bốn giờ sau khi quan sát) bằng cách sử dụng các thuật toán MW-IR kết hợp với dữ liệu TRMM TMI, Aqua AMSR-E, DMSP SSM / I và SSMIS, NOAA-19 AMSU, MetOp-A AMSUGEO IR. Thuật toán điện toán đám mây toàn cầu kết hợp dữ liệu IR chiết xuất từ dữ liệu, dữ liệu hồng ngoại được sử dụng chiết xuất từ dữ liệu vệ tinh MTSAT. (Xem hình 3)

Như vậy, các mô hình kết hợp dữ liệu viễn thám hồng ngoại và viễn thám radar để chiết xuất lượng mưa được nghiên cứu và sử dụng khá rộng rãi trên thế giới. Dưới đây, xin được giới thiệu ứng dụng của dữ liệu này trong Hệ thống phân tích lũ lụt IFAS do Nhật Bản xây dựng và phát triển.

3. Khai thác ứng dụng của dữ liệu lượng mưa gần thời gian thực từ dữ liệu viến thám Hệ thống phân tích lũ lụt IFAS (Integrated Flood Analysis System)
3.1. Thiết kế của hệ thống Phân tích lũ lụt tích hợp (IFAS)

IFAS dựa trên nền tảng thiết kế chung là hệ thống dự báo và cảnh báo lũ lụt ở các lưu vực sông, đã được phát triển trong một nghiên cứu với sự nỗ lực chung của Infrastructure Development Institude (IDI) và chín công ty tư vấn tư nhân với các mục tiêu sau:

+ Phát triển một giao diện xử lý dữ liệu lượng mưa từ ảnh vệ tinh và dữ liệu đo lượng mưa ngoài thực địa ở các trạm sẵn có trong khu vực hoặc toàn cầu để phân tích và dự báo lũ;

+ Tích hợp hai kiểu mô hình thủy văn có các tham số được cung cấp (PWRI Distributed Hydrologic Model - PDHM và Block-Wise TOP - BTOP model). Các tham số trong mô hình có thể ước tính gần đúng và sẵn có trên phạm vi toàn cầu có trong cơ sở dữ liệu GIS;

+ Có công cụ phân tích dữ liệu GIS để thiết lập các tham số cho mô hình phân tích dự báo, vì vậy không cần phải có phần mềm

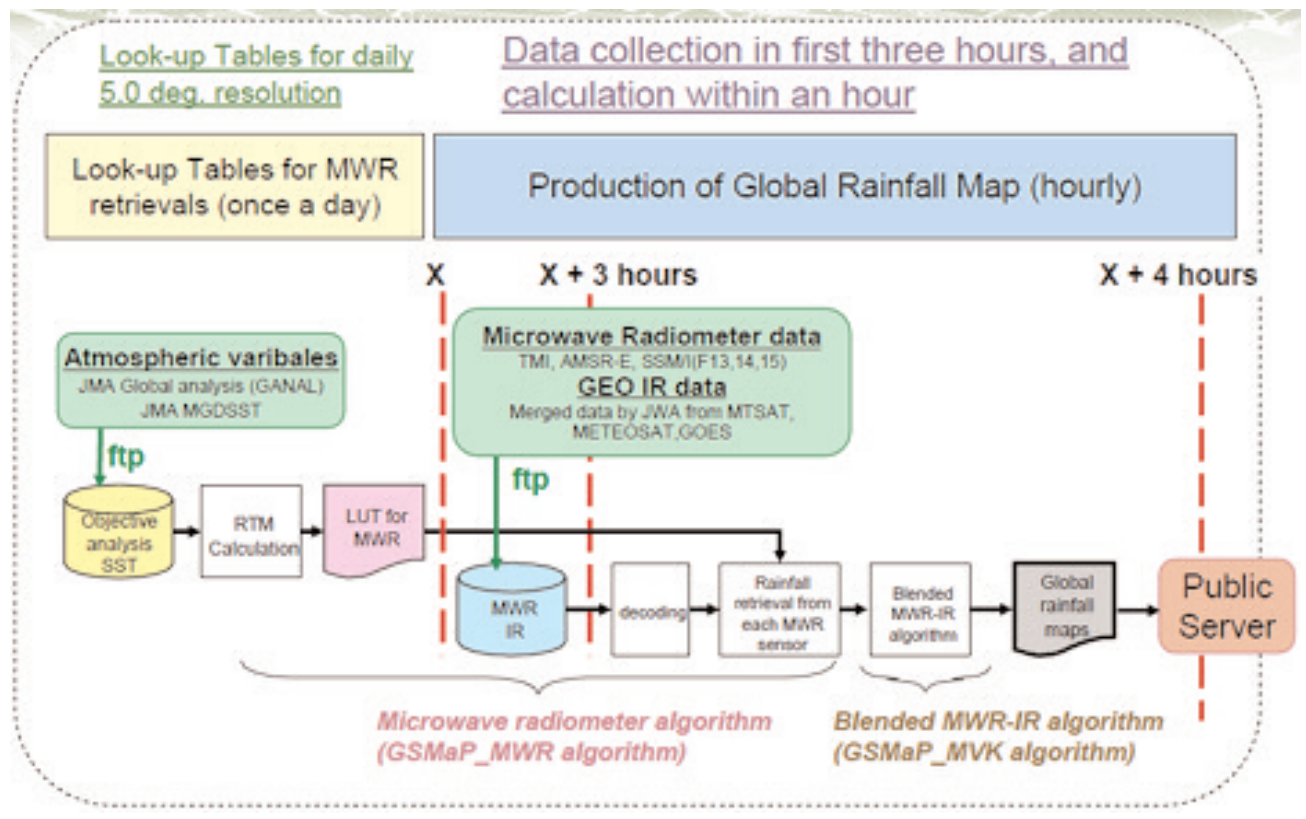

Hình 3: Quy trình của hệ thống GSMaP NRT 
GIS kèm theo;

+ Phát triển một giao diện đồ họa đơn giản, dễ thực hiện để nhập dữ liệu, mô hình hóa, phân tích dòng chảy và đưa ra dữ liệu cảnh báo;

+ Phân phối phần mềm miễn phí.

ICHARM cũng tổ chức các hội thảo kỹ thuật, đào tạo để các nước đang phát triển sử dụng các thông tin được cung cấp và các kỹ thuật một cách dễ dàng nhất. Các hoạt động trọn gói như vậy là các hoạt động then chốt nhằm xây dựng khả năng cho các nước này trong việc phân tích và dự báo lũ lụt.

\subsection{Các hợp phần của hệ thống IFAS}

Hệ thống phân tích lũ lụt tích hợp bao gồm các hợp phần sau:

+ Một hệ thống các vệ tinh quan sát lượng mưa toàn cầu: hệ thống bao gồm các vệ tinh của Mỹ, Nhật Bản quan sát lượng mưa ở các khu vực trên thế giới với tần xuất 2 lần trong ngày;

+ Dữ liệu quan sát được xử lý và cung cấp gần thời gian thực: dữ liệu này được xử lý và cung cấp theo từng khu vực trên thế giới với tần xuất nhất định;

+ Các dữ liệu GIS (địa hình khu vực, lớp phủ thực vật/sử dụng đất...) của khu vực quan sát, thông thường quan sát theo từng lưu vực sông;

+ Mô hình thủy văn, kết hợp với các dữ liệu được sử dụng để phân tích dòng chảy, đưa ra dự báo và cảnh báo ngập lụt trong lưu vực.

Toàn bộ các hợp phần của hệ thống được mô tả ở hình 4. (Xem hình 4)

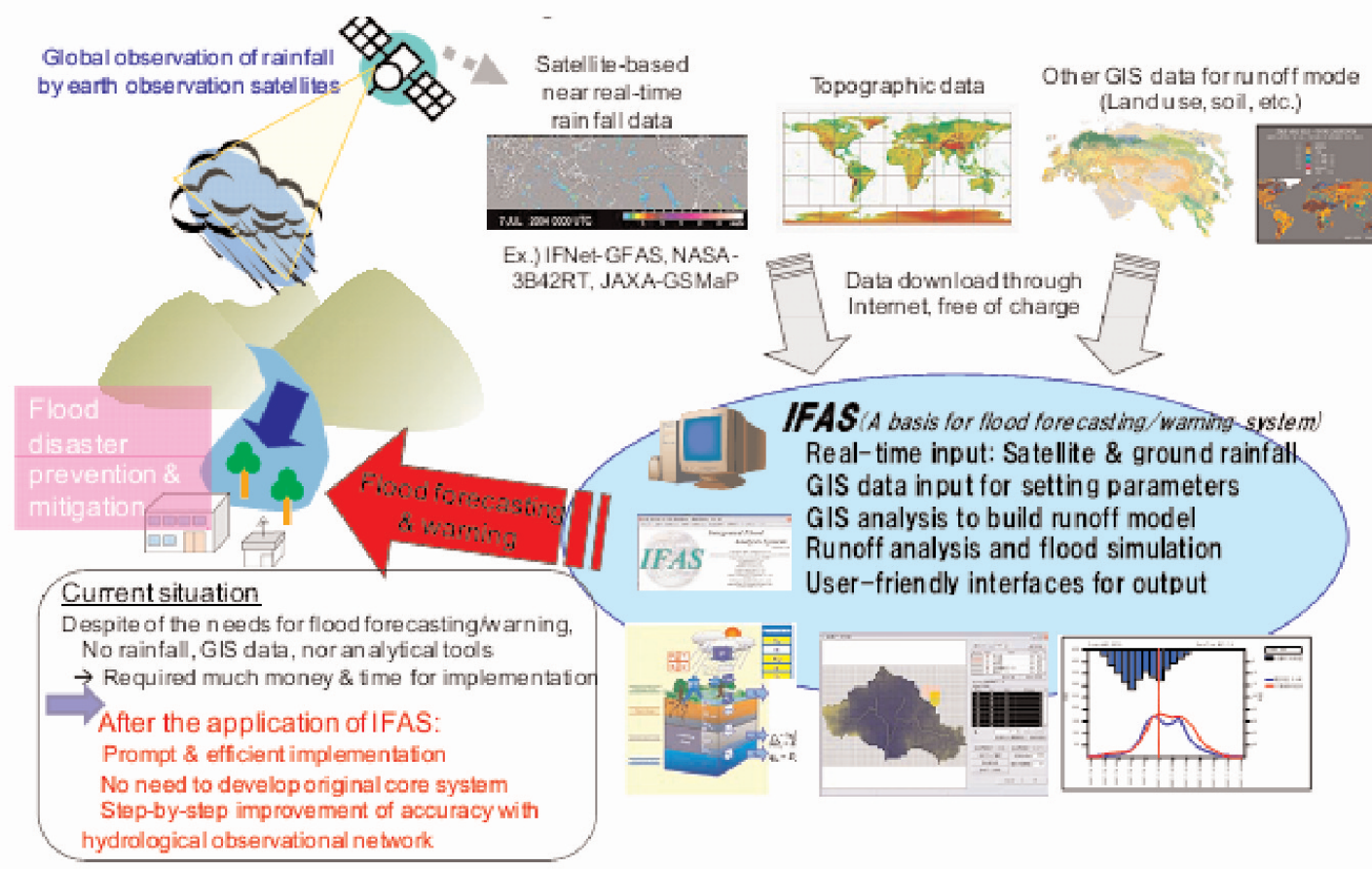

Hình 4: Hệ thống IFAS 


\section{hinh \\ 3.3. Dữ liệu lượng mưa sử dụng trong mô}

Trong các hợp phần của IFAS, có một chức năng kết hợp các dư liệu lượng mưa đo trên các trạm đo thực địa và dữ liệu dự báo lượng mưa theo thời gian thực từ vệ tinh. Các dữ liệu mưa từ vệ tinh như dữ liệu của NASA-3B42RT, NOAA-CMORPH, JAXA-GSMaP_NRT... để mô phỏng dòng chảy lũ như trong bảng 3. (Xem bảng 3 )

Trong các loại dữ liệu trên thì dữ liệu GSMaP_NRT là dữ liệu có nhiều triển vọng cho mục đích dự báo vì độ phân giải thời gian và không gian của dữ liệu cao và việc phân phối dữ liệu cũng nhanh chóng. Theo các nghiên cứu đã được khẳng định ở Nhật Bản và Mỹ thì dữ liệu GSMaP_NRT khó có thể dự đoán lượng mưa khi mưa rất to. Tuy nhiên Shiraishi et al.,2009 đã phát hiện có sự tương quan giữa yếu tố không gian và mức độ dự đoán. Dựa trên tương quan này, ông phát triển phương pháp tự hiệu chỉnh cho dữ liệu GSMaP_NRT mà không có dữ liệu đo mưa thực địa. Phương pháp này có tính thực tế và tiện dụng đối với những lưu vực sông mà có ít dữ liệu quan trắc tại các trạm, chỉ sử dụng dữ liệu dự báo lượng mưa từ ảnh vệ tinh cho công tác phân tích và dự báo lũ. Bởi vì rất khó có thể xây dựng một mạng lưới đầy đủ các trạm quan trắc lượng mưa cho một hệ thống dự báo lũ lụt.

Một nghiên cứu khác đối với trường hợp cơn bão Morakot ở Đài Loan năm 2009 thì phương pháp này có thể dự báo gần đúng nhất lượng mưa trong lưu vực sông. Tuy nhiên, trong một số trường hợp thì dữ liệu tự hiệu chỉnh về lượng mưa từ ảnh vệ tinh không tính được dòng chảy đúng, lý do là tần xuất quan trắc của vệ tinh chưa đủ dầy khi lượng mưa tăng nhanh. Vì vậy, cần phải có một hệ thống đo đạc lượng mưa toàn cầu, nhiệm vụ này đã được Mỹ và Nhật Bản lên kế hoạch để xây dựng một hệ thống vệ tinh có thể quan sát bất cứ nơi nào trong vòng 3 giờ (hiện tại là từ $5-6$ giờ).

Bảng 3: Dữ liệu lượng mưa từ ảnh vệ tinh sử dụng trong IFAS

\begin{tabular}{|l|l|l|l|}
\hline Loại dữ liệu & 3B42RT & CMORPH & GSMaP_NRT \\
\hline Nhà cung cấp & NASA/GSFC & NOAA/CPC & JAXA/EORC \\
\hline Độ phủ & $\mathrm{N} 60^{\circ}-\mathrm{S}^{\circ}$ & \multicolumn{2}{|l|}{} \\
\hline Độ phân giải & $0,25^{\circ}$ & $0,25^{\circ}$ & $0,10^{\circ}$ \\
\hline Độ phân giải thời gian & 3 giờ & 3 giờ & 1 giờ \\
\hline Độ trễ thời gian & 10 giờ & 15 giờ & 4 giờ \\
\hline Hệ tọa độ & WGS & \multicolumn{3}{|l|}{} \\
\hline Các dữ liệu lịch sử & $12 / 1997$ & $12 / 2002$ & $12 / 2007$ \\
\hline Đầu thu chụp & $\begin{array}{l}\text { TRMM/TMI } \\
\text { Aqua/ AMSR-E } \\
\text { AMSU-B } \\
\text { DMSP/SSM/I } \\
\text { IR }\end{array}$ & $\begin{array}{l}\text { Aqua/ AMSR-E } \\
\text { AMSU-B } \\
\text { DMSP/SSM/I } \\
\text { TRMM/TMI } \\
\text { IR }\end{array}$ & $\begin{array}{l}\text { TRMM/TMI } \\
\text { Aqua/ AMSR-E } \\
\text { ADEOS-2 } \\
\text { AMSR } \\
\text { IR } \\
\text { AMSU-B }\end{array}$ \\
\hline
\end{tabular}


Dưới đây là bản đồ lượng mưa được chiết tách từ vệ tinh trên phần mềm IFAS khu vực miền Bắc - Việt Nam. Dữ liệu quan trắc liên tục $1 \mathrm{~h}$.
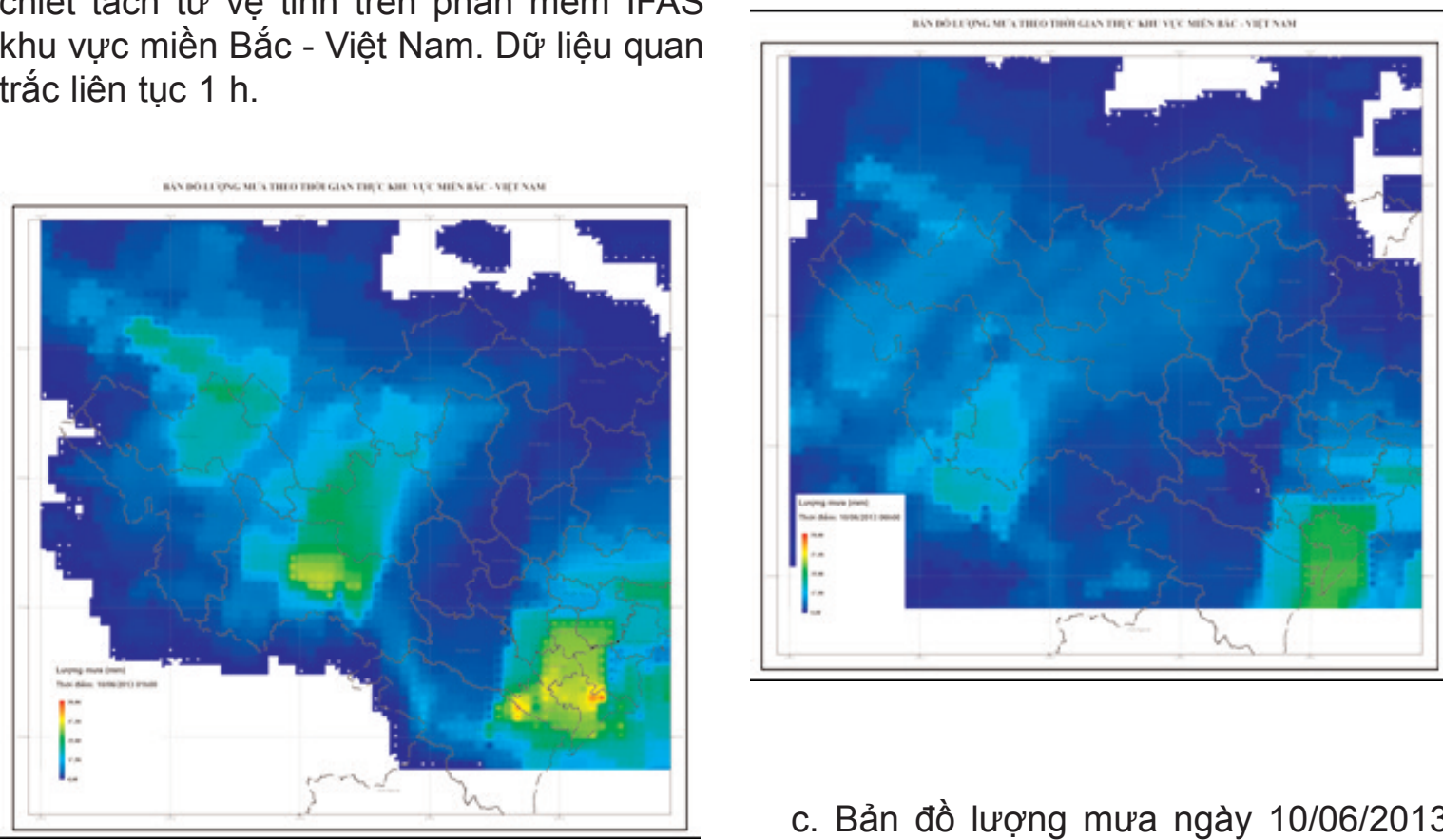

a. Bản đồ lượng mưa ngày 10/06/2013 lúc $1 \mathrm{~h}$

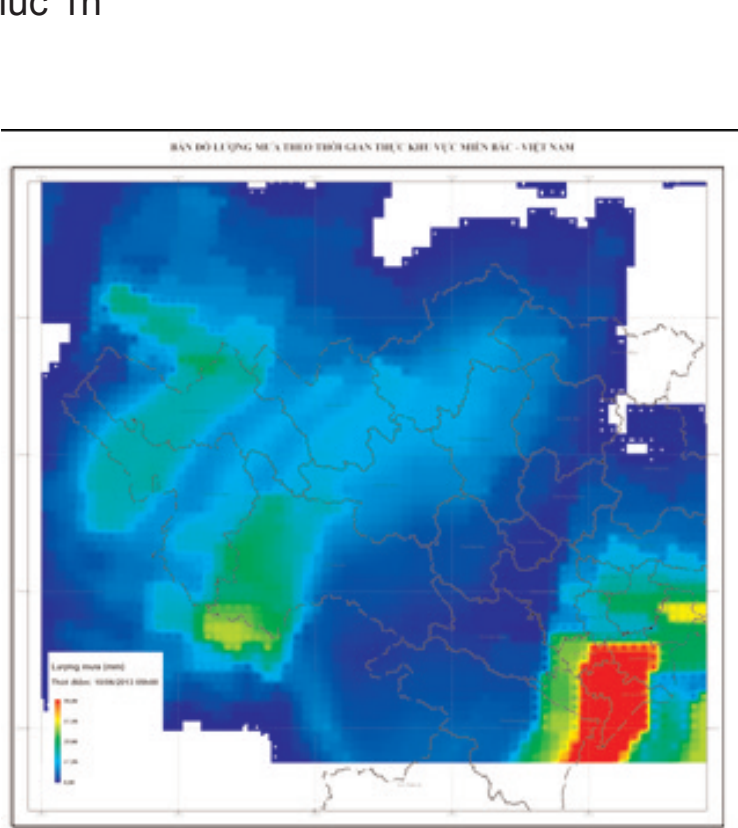

c. Bản đồ lượng mưa ngày 10/06/2013 lúc $6 \mathrm{~h}$

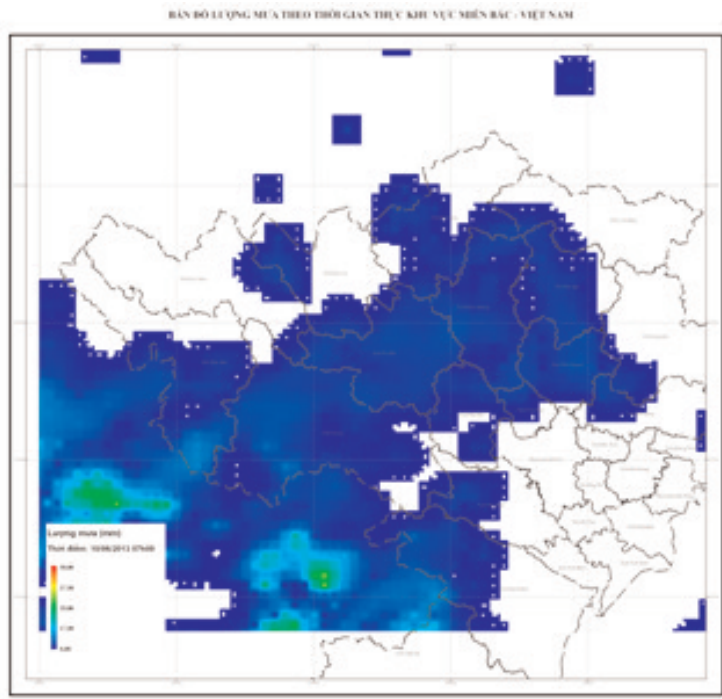

d. Bản đồ lượng mưa ngày 10/06/2013 lúc $7 \mathrm{~h}$

b. Bản đồ lượng mưa ngày 10/06/2013 lúc 5 h

Hình 5: Bản đồ lượng mưa theo giờ ngày 10/6/2013 khu vực miền Bắc - Việt Nam 


\section{Kết luận}

Sử dụng công nghệ viễn thám trong quan trắc mưa đang đóng vai trò ngày càng quan trọng trong nghiên cứu, giám sát, dự báo và cảnh báo thiên tai. Với việc không phụ thuộc quá lớn vào dữ liệu quan trắc thực địa, kết quả xử lý nhanh chóng, đây đang là một phương pháp tiên tiến cần được nghiên cứu áp dụng hơn nữa trong thời gian tới đặc biệt là trong điều kiện ở nước ta. Đặc biệt, công nghệ viễn thám chiết tách lượng mưa trong thời gian gần thực có vai trò và ý nghĩa hết sức quan trọng trong cảnh báo thiên tai nhất là trong bối cảnh biến đổi khí hậu đang diễn ra ngày càng phức tạp. Đồng thời, dữ liệu quan trắc lượng mưa bằng công nghệ viễn thám sẽ được bổ sung cho các mô hình tính toán, dự báo thời tiết. $\mathrm{O}$

\section{Tài liệu tham khảo}

[1]. Dvorak, V.F., 1984: "Tropical cyclone intensity analysis using satellite data"

\section{Summary}

\section{Exploitation of near real-time rainfall data from remote sensing image for flooding management, forecast and warning in Integrated Flood Analysis System (IFAS)}

\section{Dr. Nguyen Xuan Lam, Dr. Le Quoc Hung, BSc. Le Minh Son}

\section{Vietnam National Remote Sensing Agency}

Rainfall data is important data for planning water resources management as well as reducing the impacts caused by natural disasters. Currently, rainfall observation includes main methods such as on-site, using weather radar or remote sensing technology. Although two first methods have high accuracy but encountered great difficulty for measuring at rugged areas, mountains and sea. Meanwhile, the method by using remote sensing technology is being studied and flourished, becoming a useful tool in water resources management and reducing damage caused by natural disasters; especially, impacted situation of climate change more seriously. In particular, rainfall measurement by using remote sensing technology can be combined with monitoring, forecasting and warning models of natural disasters such as floods and droughts. This focused to describe the method of near realtime rainfall extraction by using remote sensing technology in combination with infrared and radar remote sensing data. At the same time, the use of extracted rainfall data was also introduced through flood analysis system integration - IFAS (Integrated Flood Analysis System). 0

\section{Ngày nhận bài: 26/7/2013.}

